ARTIGO

\title{
NEOFASCISMO E NEOLIBERALISMO: O FENÔMENO BOLSONARO
}

\author{
Matheus de Carvalho Barros'
}

RESUMO: É possível classificar Jair Bolsonaro como um neofascista? A partir desta pergunta, o objetivo do trabalho é analisar a ascensão do presidente do Brasil e a suas possíveis relações com a ideologia fascista/neofascista. Além disso, iremos analisar como o capitalismo neoliberal cria as condições para o surgimento e o desenvolvimento de movimentos reacionários, identificando, desta forma, uma verdadeira "afinidade eletiva" entre o neoliberalismo e o neofascismo. Para tal empreitada, utilizaremos como referência metodológica o conceito de fascismo produzido no campo do marxismo, assim como, textos de autores de relevância no cenário nacional e internacional nos estudos sobre o movimento fascista, apontando as semelhanças e particularidades do bolsonarismo em relação aos outros movimentos de extrema direita pelo mundo.

PALAVRAS-CHAVES: Jair Bolsonaro; Neofascismo; Neoliberalismo

\section{NEOFASCISM AND NEOLIBERALISM: THE BOLSONARO PHENOMENON}

ABSTRACT: Is it possible to classify Jair Bolsonaro as a Neofascist? From this question, the objective of the work is to analyze the rise of the president of Brazil and its possible relations with the fascist / neofascist ideology. In addition, we will analyze how neoliberal capitalism creates the conditions for the emergence and development of reactionary movements, thus identifying a true "elective affinity" between neoliberalism and neofascism. For this endeavor, we will use as a methodological reference the concept of fascism produced in the field of Marxism, as well as texts by authors of relevance on the national and international scene in studies on the fascist movement, pointing out the similarities and

${ }^{1}$ Graduando em Sociologia pela Universidade Federal Fluminense (UFF) particularities of Bolsonarism in relation to other movements extreme right across the world.

KEYWORDS: Jair Bolsonaro; Neofascism; Neoliberalism 


\section{INTRODUÇÃO}

A discussão em torno do tema do fascismo retoma a sua atualidade quando observamos a ascensão de movimentos e partidos de extrema direita em diversas partes do mundo. O partido Vlams Belong na Bélgica, Matteo Salvini na Itália, o FPÖ na Áustria, Donald Trump no EUA, Marine Le Pen na França e Jair Bolsonaro no Brasil, são alguns exemplos. Contudo, em cada país e em cada contexto social, esta extrema direita se expressa de formas diferentes e possui suas particularidades. A caracterização como fascista ou neofascista, por exemplo, pode se aplicar a alguns, mas não a todos. Como nos aponta Lowy (2019), algumas dessas forças emergentes têm características diretamente fascistas: é o caso do partido "Aurora Dourada" na Grécia, da CasaPound na Itália, e de vários outros partidos nacionalistas nos países bálticos. Nesse sentido, o surgimento dessa direita radical é certamente uma das características mais notáveis de nosso momento histórico.

O importante historiador italiano Enzo Traverso, em sua obra "The new faces of fascism", sustenta que o termo "fascismo" é insuficiente, ou até mesmo inapropriado, para se compreender esta nova realidade. Nessa perspectiva, Traverso propõe a utilização do conceito de "pós-fascismo" para captar as especificidades desta extrema direita ascendente. Com essa concepção, o historiador italiano quer descrever "um fenômeno em transição, um movimento ainda em transformação e ainda não cristalizado" (TRAVERSO, 2019, p. 14).

Nesse cenário, Traverso (2019) ainda salienta a importância de distinguir o "pós-fascismo" do "neofascismo". Para o historiador, o neofascismo seria uma tentativa de perpetuar e regenerar o "velho fascismo", pregando abertamente uma continuidade ideológica com o chamado fascismo histórico. Um exemplo disso seria o surgimento de alguns movimentos e partidos na Europa central, como o Jobbik na Hungria. Por outro lado, o pós-fascismo, em muitos dos casos, nasce como uma herança do fascismo clássico, contudo, vem mudando as suas formas. Segundo Traverso, apesar de suas origens, esses movimentos classificados por ele como pós-fascistas não apelam a essa "ancestralidade" e nem reivindicam a sua herança. E esse seria o fator fundamental que os distinguem do neofascismo. 
Entretanto, o conceito de "pós-fascismo" é criticado por Michael Lowy no seu texto "Conservadorismo e extrema direita na Europa e no Brasil" (2015). O sociólogo brasileiro considera inadequada a utilização do termo para caracterizar determinados movimentos de extrema direita. Segundo Lowy, o prefixo "pós" - como, por exemplo, "pósmodernidade" - teria pelo menos dois significados comuns: a passagem de uma época histórica e a ruptura com um modo de pensar. Desta forma, o conceito de "pós-fascismo" implicaria, implícita ou explicitamente, em uma hipótese que na visão do sociólogo marxista seria errônea: a ideia de que o fascismo pertenceria a uma época ultrapassada. No entanto, para Michael Lowy, o fascismo não é uma época, mas um modo de organização e uma ideologia política, que se manifesta e se manifestou de diversas maneiras, bem depois do fim do Terceiro Reich.

No texto "Neofascismo: um fenômeno planetário - o caso Bolsonaro" (2019), Lowy define como neofascistas líderes, partidos e movimentos que têm semelhanças significativas com o fascismo clássico dos anos 1930, mas que possuem também as suas particularidades. Estes seriam fenômenos novos que não são idênticos aos do passado, justamente por carregarem as especificidades do século XXI. Como exemplo para a sua concepção de movimentos e partidos neofascistas, Michael Lowy (2019) cita o caso do partido Vlams Belong na Bélgica, Matteo Salvini na Itália, o FPÖ na Áustria e a figura de Jair Bolsonaro no Brasil. Desse modo, é possível identificar que na concepção do sociólogo brasileiro, diferentemente de Enzo Traverso, esses movimentos, líderes e partidos não precisam necessariamente reivindicar a herança do fascismo histórico para se constituírem como fenômenos neofascistas. Nessa configuração, o fascismo consiste em um conceito - assim como bem definiu o historiador argentino Federico Finchelstein (2017) - transnacional, transatlântico e transhistórico.

Muitos estudiosos tendem a classificar a nova extrema direita ascendente como populista. Todavia, como argumenta Traverso (2019), o conceito de populismo foi tão amplamente usado que suscita um robusto e justificado ceticismo. Devido a sua livre flutuação e seus limites abrangentes, torna-se difícil falar do populismo como um 
fenômeno político que possua um perfil e uma ideologia própria. Há certo consenso na historiografia em classificar como populistas alguns fenômenos do século XIX, como o populismo russo representado pelos Narodniks, assim como o populismo latino-americano da primeira metade do século XX, encarnado nos governos de Perón na Argentina e Getúlio Vargas no Brasil. Nesse sentido, como aponta Michael Lowy (2015), o termo populismo correspondia a algo bem específico: governos nacionais populares ou movimentos construídos em volta de figuras carismáticas, com amplo apoio popular e uma retórica antiimperialista. Esta retórica também busca exaltar as virtudes do povo em relação ao establishment político, com o objetivo de mobilizar as massas contra o "sistema". Desta forma, o populismo seria mais um estilo político do que propriamente uma ideologia política (TRAVERSO, 2019).

Nos últimos anos, muitas figuras foram classificadas como populistas: Marine Le Pen na França, Jeremy Corbin no Reino Unido, Matteo Salvini na Itália, Donald Trump nos EUA, Hugo Chávez na Venezuela, Evo Morales na Bolívia e Jair Bolsonaro no Brasil. Diante de enormes diferenças entre as figuras citadas, o termo populismo acaba se tornando uma "concha vazia" - termo utilizado por Enzo Traverso (2019) - que pode ser preenchida por conteúdos políticos díspares. O historiador Federico Finchelstein chega a definir o populismo como "uma forma autoritária de democracia que surgiu originalmente como uma reformulação do fascismo pós-guerra" (FINCHELSTEIN, 2017, p.98). Na concepção do historiador argentino, fascismo e populismo estão conectados genealogicamente. Entretanto, essa relação feita por Finchelstein dificulta o entendimento do fenômeno quando a tipologia construída pelo historiador inclui o "populismo neoclássico de esquerda", da qual fariam parte Hugo Chávez, Evo Morales e Rafael Corrêa, por exemplo. Desta forma, ao obscurecer ou até mesmo eliminar as diferenças entre direita e esquerda, o termo populismo muitas vezes acaba atrapalhando a compreensão das particularidades política e ideológica do objeto estudado.

No Brasil, a discussão sobre fascismo e neofascismo veio à tona com a eleição de Jair Bolsonaro à presidência da República. Esse debate foi colocado a público recentemente, por exemplo, quando 
Armando Boito Júnior se propôs a analisar a emergência de um movimento neofascista no Brasil (WEBER, 2019). Os artigos de Boito Júnior, publicados pelo jornal Brasil de Fato, foram inicialmente uma resposta a um texto de Atílio Borón publicado originalmente pela Página 12. Em seu artigo, Borón (2019) argumenta que é um erro grave classificar Jair Bolsonaro como um fascista. Segundo o sociólogo argentino, o fascismo é uma "categoria histórica", ou seja, possui características únicas cujas condições para o seu surgimento seriam próprias do período entre guerras. Portanto, tais condições seriam irrepetíveis no contexto atual. Em contraposição à Borón, Armando Boito (2019) acredita ser possível o surgimento do fascismo na atualidade, e destaca que essa possibilidade não pode ser descartada principalmente no cenário brasileiro. Utilizando Nicos Poulantzas como referência, o professor da Unicamp argumenta que a crise econômica e política que marcam o tempo presente, colocam a possibilidade do ressurgimento do fascismo, mesmo que o fenômeno assuma formas distintas de sua matriz histórica.

Na efervescência da discussão sobre o caráter dos movimentos de extrema direita que surgem em diversos países, levantamos a seguinte indagação: É possível classificar Jair Bolsonaro como um Neofascista? A partir desta pergunta, o objetivo do trabalho é analisar a ascensão e atuação do presidente do Brasil, tendo em vista que o movimento político encabeçado por Bolsonaro se enquadra no processo global de ascensão de uma extrema direita reacionária e autoritária nos últimos anos. Em primeiro lugar, iremos conceituar o fascismo à luz da teoria marxista. Em seguida, vamos discutir como o capitalismo neoliberal cria as condições e ambientes propícios para o surgimento e o desenvolvimento de movimentos reacionários, identificando, desta forma, uma verdadeira "afinidade eletiva" entre o neoliberalismo e o neofascismo. Por fim, iremos analisar o contexto brasileiro e as possíveis relações de Jair Bolsonaro com a ideologia fascista/neofascista, apontando as semelhanças e particularidades do bolsonarismo em relação aos outros movimentos do cenário internacional.

\section{O QUE É FACISMO?}


Como nos aponta Marcelo Badaró (2020), a bibliografia sobre o fascismo é monumental. Em seu mais recente livro intitulado "Governo Bolsonaro: neofascismo e autocracia burguesa no Brasil", o professor da UFF traz a contribuição de Fernando Rosas sobre a historiografia do fascismo. O historiador português traça um quadro cronológico, bastante útil, no qual identifica basicamente quatro fases fundamentais nas análises sobre o fenômeno fascista. A primeira delas teria ocorrido entre os anos de 1920 e 1930, protagonizada por dirigentes revolucionários comunistas, comprometidos com o combate ao fascismo. Dentre eles, destacam-se Antônio Gramsci, Clara Zetkin e Leon Trotsky. O segundo momento teria ocorrido após a Segunda Guerra mundial. Movido pelo clima da Guerra Fria, a segunda fase de reflexões sobre o fascismo emergiu através de uma interpretação que igualava os regimes fascistas ao stalinismo soviético, que ficou conhecida como a teoria do totalitarismo, representada, entre outros, por Hannah Arendt. O terceiro momento surge com a ascensão da ideologia neoliberal e da decomposição dos regimes do Leste Europeu, ao final do século XX. Essa vertente conhecida também como "novo consenso historiográfico" rejeitava em grande medida as análises centradas nos conflitos de classe e privilegiava as ideias e os aspectos culturais do fascismo (MATTOS, 2020). A quarta e última vertente historiográfica apontada por Fernando Rosas são os debates em processo na contemporaneidade, marcados pela construção de uma teoria crítica do fascismo assente em pressupostos distintos (neomarxistas, pós-estruturalistas ou antropologia social), mas que têm em comum, como ponto de partida, "a demarcação do tal novo consenso em torno do fascismo como transcendência idealista, ou seja, assente na exclusão do condicionamento das expressões do político e ideológico" (ROSAS, 2019, p. 21).

Contudo, no presente trabalho utilizaremos como referência o conceito de fascismo produzido no campo do marxismo, mais especificamente as contribuições de Leon Trotsky sobre a ascensão do nazismo na Alemanha escritas entre 1930-1933.

Exilado em uma ilha turca, após as eleições de 1930, Trotsky escreve seu primeiro texto sobre a conjuntura política alemã. Em "O Giro da Internacional Comunista e a Situação Alemã", o revolucionário 
russo já identificava que sob os golpes da crise, as eleições mostraram que a pequena burguesia estava se inclinando não para a revolução proletária, mas sim para uma reação imperialista extremada, arrastando consigo importantes camadas do proletariado. Analisando os resultados dos votos daquele ano, Trotsky (2018) argumenta que o crescimento gigantesco do Nacional-Socialismo é fundamentalmente expressão de dois fatos. Em primeiro lugar, da crise social profunda que lança as massas pequeno burguesas para fora de seu equilíbrio e, por outro lado, expressa a ausência de um partido revolucionário que pudesse se apresentar as massas populares como agente transformador da realidade concreta.

Nessa perspectiva, é possível dizer que o "fascismo histórico", tanto na Itália como na Alemanha, é produto de uma severa e sistémica crise do capitalismo monopolista, onde a acumulação do capital sob os marcos da democracia burguesa é progressivamente minada. Em consequência dessa crise econômica e política, há um descontentamento cada vez maior entre as camadas sociais médias, mais especificamente entre a pequena burguesia que passa a se engajar em movimentos de massas reacionários e violentos (MANDEL, 1995).

Nesse sentido, analisando a conjuntura alemã, Trotsky salienta que o movimento liderado por Hitler é análogo em geral ao fascismo italiano. Ou seja, o nazismo seria "um movimento de massas, com seus líderes usando grandes quantidades da retórica socialista. E isto é necessário para a criação de um movimento de massas" (TROTSKY, 2018, p. 12). Desse modo, o autor de "A História da Revolução Russa" é enfático ao dizer que: "A base genuína do fascismo é a pequena burguesia. Na Itália, ela tem uma base muito grande - a pequena burguesia das cidades e vilas, e do campesinato. Na Alemanha, igualmente, há uma ampla base para o fascismo" (TROTSKY, 2018, p. 12).

Desta forma, para Leon Trotsky o fascismo - diferentemente de outros movimentos contrarrevolucionários e regimes ditatoriais - seria em primeira instância um movimento reacionário de massas da pequena burguesia revoltada. Impulsionados pela profunda crise do capital monopolista, este movimento apresenta uma combinação de 
um nacionalismo extremo e uma manifestação verbal demagógica anticapitalista com uma hostilidade ainda maior contra o movimento operário organizado.

Todavia, apesar de sua base social, uma vez no poder, tanto o fascismo italiano quanto o nazismo alemão não foram os governos da pequena burguesia, mas sim os do grande capital (MATTOS, 2020). Em um texto escrito em 1933, Trotsky ilustra muito bem essa conjuntura: O fascismo alemão, assim como o italiano, se ergueu ao
poder nas costas da pequena-burguesia, que foi tornada
bode expiatório contra as organizações da classe
trabalhadora e as instituições democráticas. Mas o
fascismo no poder é tudo menos o governo da pequena
burguesia. Pelo contrário, ele é a ditadura mais impositiva
do capital monopolista. Mussolini tem razão: as classes
médias são incapazes de políticas independentes. Durante
os períodos de grande crise, são invocadas a seguir aos
absurdos das políticas de uma das duas classes
fundamentais. O fascismo conseguiu coloca-los a serviço
do capital. Slogans como o controle estatal dos fundos
financeiros e a supressão de lucros não oriundos do
trabalho foram abandonados assim que se chegou ao
poder. Pelo contrário, o particularismo da pequena
burguesia deu lugar ao centralismo policial capitalista.
Cada sucesso interno e externo das políticas do nazismo
significará inevitavelmente o sufocamento do pequeno
capital pelo grande (TROTSKY, 2018, p. 227).

Nessa perspectiva, segundo Marcelo Badaró (2020), o sentido de classe dos regimes políticos fascistas - como "ditadura do capital monopolista" - se expressa não apenas em suas políticas econômicas em benefícios do grande capital, mas especialmente em sua violência contra as organizações autônomas da classe trabalhadora. No texto " $E$ agora? A revolução alemã e a burocracia", escrito na primeira metade de 1932, Leon Trotsky argumenta que o fascismo não é simplesmente um sistema de repressão, de ato de força e de terror policial. O fascismo seria um "sistema de Estado particular, baseado no extermínio de todos os elementos da democracia proletária na sociedade burguesa" (TROTSKY, 2018, p. 55). Desse modo, para o revolucionário russo, a tarefa do fascismo não consistia apenas na destruição da vanguarda proletária, mas também em manter toda a classe trabalhadora em estado fragmentário. Para tal empreitada, a 
eliminação física da fração mais revolucionária do movimento operário era insuficiente. Trotsky aponta que seria necessário também destruir todos os pontos de apoio e de organização do proletariado e exterminar os resultados de anos de trabalho da social-democracia, dos sindicatos e, claro, do Partido Comunista.

Desta forma, para o revolucionário russo, a especificidade da "fascistização" do Estado consistia em

\begin{abstract}
destruir as organizações operárias, reduzir o proletariado a um estado amorfo, criar um sistema de organismos que penetre profundamente nas massas e esteja destinado a impedir a cristalização independente do proletariado. É nisto que consiste a essência do regime fascista (TROTSKY, 2018d, p. 66).
\end{abstract}

Portanto, após esta brevíssima análise dos escritos de Trotsky produzidos entre 1930 e 1933, podemos argumentar que, resumidamente, o fascismo seria fruto de uma severa e sistémica crise do capital monopolista, onde seu processo de valorização se encontra minado nos marcos da democracia parlamentar burguesa. Concomitantemente a esta crise social, política e econômica, há um notório descontentamento entre as camadas médias da sociedade, mais especificamente entre a pequena-burguesia que passa a se engajar em organizações e movimentos de massas fundamentalmente violentos e reacionários. Autônomos em um primeiro momento, com o desenrolar da conjuntura esses movimentos passam a ser instrumentalizados em grau cada vez maior pelo grande capital em sua tentativa de aniquilar o movimento dos trabalhadores e salvaguardar a sociedade burguesa.

\title{
O CAPITALISMO NEOLIBERAL E A ASCENSÃO DA EXTREMA DIREITA
}

No plano internacional, é difícil propor uma explicação geral que possa dar conta de fenômenos que, apesar de suas semelhanças, possuem indiscutíveis particularidades. Entretanto, é possível levantar algumas hipóteses que nos permitem elucidar, pelo menos em parte, a base material da ascensão da extrema direita ao redor do mundo. 
A primeira hipótese que podemos apontar é o próprio processo de globalização capitalista neoliberal, que acaba por produzir e reproduzir, em escala planetária, o que Daniel Bensaid denominou de "pânico identitário". Esse processo acaba alimentando uma obsessiva procura por fontes e raízes que leva a formas chauvinistas de religião, formas religiosas de nacionalismo, além de alimentar conflitos étnicos e confessionais (BENSAID, 2005; LOWY, 2019).

O outro fator a ser levantado, que está diretamente associado ao processo de hegemonia mundial - neoliberal - do capital financeiro, é a crise geral do capitalismo de 2008. Luiz Filgueiras e Graça Duck (2019) argumentam que não apenas a crise em si, mas também a resposta dada pelos diferentes Estados nacionais (socialização dos prejuízos do sistema financeiro, através do endividamento dos Estados) e, na sequência, o aprofundamento das políticas e reformas neoliberais nos países de capitalismo periférico (principalmente a partir da crise da zona do euro em 2010), se configuram como a base material da ascensão de uma nova direita e extrema direita em escala planetária.

Michael Lowy (2019) destaca que tanto o processo de globalização quanto a crise de 2008 se tornaram possíveis em uma sociedade capitalista na qual o neoliberalismo opera desde 1980, aprofundando as desigualdades, as injustiças sociais e concentrando riquezas - assim como ocorreu no capitalismo liberal pré-1929.

O predomínio do neoliberalismo como prática política e ideologia não significou apenas uma guerra sem fim contra o socialismo, mas representou também um combate à própria democracia (IANNI, 1998). Segundo Pierre Dardot e Christian Laval (2016), compreender politicamente o neoliberalismo pressupõe que se compreenda a natureza do projeto social e político que ele representa e promove desde os anos 1930. Em sua origem, o pensamento neoliberal traz em si uma ideia muito particular de democracia que sob muitos aspectos, deriva de um antidemocratismo: "O direito privado deveria ser isentado de qualquer deliberação e qualquer controle mesmo sob forma de sufrágio universal" (DARDOT E LAVAL, 2016, p. 9). Portanto, nesta perspectiva, é possível dizer que o neoliberalismo é intrinsecamente antidemocrático. 
Sobre a relação entre neoliberalismo e democracia, Reginaldo Moraes (1998) é enfático ao dizer que o neoliberalismo não tem meias palavras para nomear seus inimigos: a democracia de massas, o Estado de bem-estar social e os sindicatos. O filósofo brasileiro argumenta que o neoliberalismo econômico leva a uma política conservadora, e seus propagandistas, como Friedrich Hayek, jamais esconderam a pretensão de colocar limites drásticos às "irresponsabilidades" da democracia de massas. Nessa linha de raciocínio, Ludwig Von Mises, outro importante teórico do neoliberalismo, em sua obra Liberalismo segundo a tradição clássica, chega a dizer, por exemplo, que o fascismo teve um importante papel ao "salvar" a civilização europeia. Nas próprias palavras do economista da Escola austríaca:

\begin{abstract}
Não se pode negar que o fascismo e movimentos semelhantes, visando ao estabelecimento de ditaduras, estejam cheios das melhores intenções e que sua intervenção, até o momento, salvou a civilização europeia. O mérito que, por isso, o fascismo obteve para si estará inscrito na história. Porém, embora sua política tenha propiciado salvação momentânea, não é do tipo que possa prometer sucesso continuado. O fascismo constitui um expediente de emergência. Encará-lo como algo mais seria um erro fatal (MISES, 1987, p.23).
\end{abstract}

Ao transformar o capitalismo, o neoliberalismo transformou profundamente as sociedades. Nesse sentido, como nos apontam Dardot e Laval (2016), o neoliberalismo não é apenas uma ideologia ou um tipo de política econômica. É um sistema normativo que ampliou sua influência ao mundo inteiro, estendendo a lógica do capital a todas as relaç̃̃es sociais e a todas as esferas da existência humana. Os autores de "A nova razão do mundo" (2016) ainda chamam atenção para o fato de que além das consequências políticas, econômicas e sociais, não podemos ignorar as mutações subjetivas provocadas pelo neoliberalismo. Essas transformações podem ser visualizadas em um crescente egoísmo social, que nega as formas de solidariedade e redistribuição, e que é capaz de desembocar em movimentos reacionários e ou até mesmo neofascista.

Nesse cenário, foi a direita e a extrema direita que conseguiram capturar o ressentimento dos "perdedores" do processo de mundialização do capital nos últimos quarenta anos (conduzido pela 
ideologia neoliberal) e direcioná-los contra inimigos imaginários e o establishment em geral (FILGUEIRAS; DUCK, 2019). Esse ressentimento é derivado do desemprego, da pobreza, da precarização do trabalho e das condições de vida muitas vezes degradante.

No texto "O neoliberalismo neofascista do governo Bolsonaro" (2019), Luiz Filgueiras e Graça Duck argumentam que a incapacidade do liberalismo clássico e da socialdemocracia em apresentar alternativas concretas ao ultraliberalismo e suas consequências sociais, facilitou o crescimento de movimentos neofascistas. Nesse sentido, como bem colocam os professores da UFBA, para além das aparências e da retórica, há uma clara convergência política, ou até mesmo uma "afinidade eletiva", entre o neoliberalismo, enquanto expressão dos interesses do capitalismo financeiro, e a atual ascensão da extrema direita, que em seu limite se apresenta como neofascista.

Como o programa e as políticas neoliberais não têm o que oferecer à esmagadora maioria da população, a democracia liberal e o Estado de direito acabam se chocando com os interesses do capital financeiro. Nessa perspectiva, essa "relação simbiótica" entre neoliberalismo e neofascismo acaba criando um contexto em que cada vez mais se torna necessário um Estado de exceção. Pois, como nos demonstram os professores da UFBA em "O governo Bolsonaro, o Neofascismo e a resistência democrática" (2018), ao não conseguir incorporar em seu movimento a grande massa da população, o capitalismo financeiro neoliberal tem dificuldades de conviver com a participação política dos "subalternos", e consequentemente, com as próprias instituições democráticas. Desse modo, a própria democracia e o Estado de direito se constituem como empecilhos para a reprodução do capital. O capitalismo neoliberal cria e reproduz circunstâncias e ambientes propícios para o surgimento de movimentos autoritários, reacionários e neofascistas.

Portanto, apesar das singularidades históricas, políticas, econômicas e sociais de cada país, há um fio condutor comum que gera um cenário favorável à ascensão de líderes, movimentos e partidos de extrema direita, ou até mesmo neofascista, em diversas partes do mundo. Este fio condutor reside nas condições materiais de 
vida da sociedade, que é a base real dos conflitos entre classes (FILGUEIRAS E DUCK, 2019).

\section{O CONTEXTO BRASILEIRO}

No cenário brasileiro, é possível identificar a explosão das manifestações massivas de 2013 - ocorridas nas principais cidades do país - como um dos fenômenos decisivos para a inflexão da atual conjuntura (FILGUEIRAS; DUCK, 2019). O movimento que em sua origem protestava contra o aumento das tarifas dos transportes públicos, logo se direcionou à crítica das condições dos serviços públicos em geral. Luis Filgueiras e Graça Duck argumentam que na esteira dessas manifestações aparecem sinais claros da desqualificação e demonização da política, dos partidos políticos e dos próprios políticos. Na concepção dos professores da Universidade Federal da Bahia, esses movimentos de contestação foram sintetizados na "luta contra a corrupção", que se desdobrou, posteriormente, em um ataque direto ao Estado brasileiro, "mas sobretudo ao Estado Social, e a tudo o que é público e coletivo, tendo como contraposição o individualismo e a meritocracia" (FILGUEIRAS; DUCK, 2019, p. 3). Nesse sentido, esta

seria uma das origens da conjunção entre neoliberalismo e neofascismo que viria a se desenvolver nos anos seguintes.

A vitória eleitoral de Dilma Rousseff em 2014, marcada por eleições extremamente polarizadas, já expressava a mudança de conjuntura engendrada pelas manifestações do ano anterior. Contudo, para além dos acontecimentos de 2013, e das eleições de 2014, há razões mais profundas que explicam as transformações do cenário brasileiro. Como nos apontam Luís Filgueiras e Graça Duck, essas mudanças podem ser identificadas no impacto continuado da crise mundial do capitalismo no Brasil, que se tornam mais visíveis a partir de 2011. A desaceleração do crescimento, ano a ano, ligada à política de desoneração tributária para inúmeros setores da economia dada ainda pelo primeiro Governo Dilma, gerou um déficit primário a partir de 2014. Somado a isso, a execução da política de ajuste fiscal a partir de 2015, logo no início do segundo mandato de Dilma Rousseff, levou a economia à recessão, elevando rapidamente as taxas de desemprego (FILGUEIRAS; DUCK, 2019). 
Nesta nova conjuntura econômica de aumento do desemprego e queda de rendimentos, a insatisfação política com o governo se amplia, preparando um terreno propicio para o discurso neoliberal e sua contestação das políticas sociais promovidas pelos governos do Partido dos Trabalhadores. Nesse sentido, a ofensiva da burguesia cosmopolita, para retomar o seu protagonismo no bloco do poder, que foi reduzido parcialmente devido às relações privilegiadas do PT com a burguesia nacional, obteve êxito. Instrumentalizada historicamente pela burguesia associada ao capital internacional, a bandeira da anticorrupção foi mais uma vez utilizada como "a ponta de lança" desta ofensiva, mobilizando a massa da classe média brasileira para o apoio ao golpe parlamentar que pôs fim ao Governo Dilma em 2016 (FILGUEIRAS; DUCK, 2019).

Segundo Luís Felipe Miguel (2017), a destituição da presidente Dilma Rousseff, provisória em maio e definitiva em setembro de 2016, sem que houvesse crime de responsabilidade claramente estabelecido, marca uma fratura crucial no "ensaio" democrático iniciado pouco mais de três décadas no país. Entretanto, como assinala Marcelo Braz (2017), o impeachment de Dilma não se configura como um "golpe clássico", uma vez que ele ocorre dentro do funcionamento das instituições burguesas, ou seja, com o aval e apoio da justiça e do legislativo. Nessa perspectiva, o professor da UFRJ argumenta que o impeachment vem se constituindo, especialmente na América Latina, em uma forma "democrática" de depor governos que, embora já tenham servido aos interesses do grande capital, já não servem ou se tornaram obstáculos em alguma medida. Nas palavras do autor: "foi assim, um golpe nas ilusões democráticas geradas pelos limites próprios da ordem burguesa, cuja condição cria suas próprias ilusões" (BRAZ, 2017, p.89).

Neste contexto, a extrema direita veio à "luz do dia". O resultado deste processo acabou por desembocar na eleição de Jair Bolsonaro em 2018. A radicalização da polarização política, que vinha desde a eleição anterior de 2014, se aprofundou e engoliu a direita tradicional que conspirou e participou ativamente do golpe, abrindo espaço para a extrema direita reacionária, mobilizadas por discursos misóginos, racistas, elitistas, e com claras inspirações fascistas (FILGUEIRAS; DUCK, 2019). 


\section{BOLSONARO, NEOFACISMO E NEOLIBERALISMO}

Em um texto publicado originalmente no jornal Página 12, Atílio Boron (2019) se recusou a caracterizar Jair Bolsonaro como fascista, e também desconsidera a possibilidade do governo brasileiro se converter em um regime fascista. O sociólogo argentino sustenta que o fascismo é um fenômeno histórico único, restrito à Europa das décadas de 1920 e 1930, e desse modo, irrepetível. Se contrapondo a Boron, o cientista político brasileiro Armando Boito Jr escreve uma série de artigos publicados pelo jornal Brasil de Fato, argumentando que o fascismo não pode ser excluído das possibilidades existentes na atual conjuntura brasileira. Utilizando Nicos Poulantzas como referência, o professor da Unicamp argumenta que a crise econômica e política que marcam o tempo presente, colocam a possibilidade do ressurgimento do fascismo, mesmo que o fenômeno assuma formas distintas de sua matriz histórica.

Um dos principais argumentos de Atílio Boron (2019) é que o fenômeno fascista seria irrepetível pois seu protagonista, a burguesia nacional, teria desaparecido devido o processo de internacionalização do capitalismo. Boito Júnior (2019) contesta essa afirmação argumentando que, uma ditadura fascista em um país imperialista não terá o mesmo "bloco no poder" que um regime fascista instaurado em um país cuja economia e o Estado são dependentes. O professor da Unicamp assinala que, teoricamente, é possível contemplar a hipótese de que um eventual Estado fascista no Brasil venha servir os interesses do capital internacional, e não da burguesia nacional como ocorreu no fascismo histórico. Portanto, é possível dizer que fascismo e neoliberalismo não são excludentes.

As definições de fascismo são sempre problemáticas e complexas. Contudo, em sua argumentação Armando Boito Júnior (2019) defende que, em sua essência, o fascismo seria um movimento reacionário de massas enraizado em classes intermediárias das formações sociais capitalistas. Todavia, apesar de suas origens nas classes médias, o fascismo chega ao poder não necessariamente como representante de tais classes, mas sim, após ter sido cooptado politicamente pela burguesia, ou pelo menos por alguma de suas 
frações, com o objetivo de instaurar um governo antidemocrático e antipopular (BOITO JR, 2019).

Para além de uma forma de Estado ditatorial, o fascismo também é uma ideologia e um movimento. Para Armando Boito, uma ditadura fascista só se torna realidade se houver um movimento social que seja movido pela ideologia fascista, e que assuma o papel para a sua implantação. Desse modo, não se restringindo a uma forma de Estado, é possível que os fascistas abram mão ou posterguem, em uma determinada conjuntura, a luta pela instauração de uma ditadura fascista (BOITO JR, 2019). Em "Lições sobre o Fascismo", Palimiro Togliatti demonstra que foi exatamente isso que Mussolini fez ao chegar ao poder 1922, e foi o que continuou a fazer até pelo menos 1923. Sendo assim, teoricamente é possível que um movimento fascista chegue ao poder e não implante uma ditadura fascista.

Nesse cenário, o argumento central de Armando Boito Júnior é que no Brasil de hoje temos um presidente neofascista sustentado por uma ideologia e um movimento neofascista. Todavia, não é possível dizer que existe no país um regime político fascista. Segundo o professor da Unicamp, o que temos hoje é uma "democracia burguesa deteriorada em crise" (BOITO JR, 2019, p. 4).

Segundo o historiador brasileiro Demian Melo (2019), o discurso bolsonarista apresenta características ideológicas que podem situá-lo no campo do fascismo. É possível localizar em Bolsonaro um discurso que, diante da profunda crise brasileira, promete um processo de reconstrução nacional. Em seu discurso de posse, Jair Bolsonaro diz que uma de suas missões é "restaurar e reerguer a nossa pátria, libertando-a definitivamente da corrupção, da criminalidade e da submissão ideológica" (FOLHA DE S. PAULO, 2019). Melo (2019) aponta que, enquanto Benito Mussolini apelava para a reconstrução gloriosa do império romano, e Hitler cultuava um passado mítico do povo alemão, Jair Bolsonaro e seu movimento transformam em mito o período da ditadura militar brasileira. São inúmeras as referências saudosistas que Bolsonaro faz em relação à ditadura que perdurou 21 anos no Brasil. O presidente do Brasil chegou a dizer que Carlos Alberto Brilhante Ustra - um dos mais notáveis torturadores da ditadura brasileira - era um herói nacional. Jason Stanley (2018) afirma 
que a política fascista invoca um passado mítico que tragicamente teria sido destruído. Não é demais lembrar que o próprio Bolsonaro é chamado de "mito" pelos seus seguidores.

Outro fator importante que relaciona o bolsonarismo à ideologia fascista é um anticomunismo "alimentado a partir de paranoias conspiratórias" (MELO, 2019, p. 7). Entretanto, o fascismo clássico - assombrado pelas consequências da revolução Bolchevique tinha por um dos seus objetivos a eliminação das esquerdas e de seus partidos de massa. Já no neofascismo brasileiro, a "esquerda" a ser eliminada é um movimento democrático e reformista, representado, sobretudo, pelo Partido dos trabalhadores (BOITO JR, 2020).

Além dessas características, Jair Bolsonaro também engendra um movimento social que mobiliza setores da classe média e também setores das classes subalternas, motivados por um grande ressentimento social (MELO, 2019). Todavia, uma das particularidades do bolsonarismo em relação ao fascismo clássico, que diz respeito às próprias especificidades do século XXI, é que o seu movimento social não se organiza em torno de um partido de massas. As bases bolsonaristas se articulam sobretudo pelas redes sociais. Como nos apontam Luis Filgueiras e Graça Duck (2018), é através das redes sociais que Bolsonaro se dirige diretamente às massas, sem necessitar da intermediação de partidos políticos ou qualquer outra organização da sociedade civil. Segundo os professores da UFBA, essa é justamente uma das características que distingue o neofascismo brasileiro do fascismo histórico. Os seguidores e militantes de Jair Bolsonaro não se aglutinam em torno de um partido político ou de um comando único. Nesse cenário, Demian Melo é categórico ao dizer que: "Bolsonaro é um fascista. Não é só alguém com uma personalidade fascista, com um comportamento fascista. É alguém que professa uma ideologia fascista: xenófoba, preconceituosa, machista e militarista" (MELO, 2019, p. 7).

Apesar da retórica nacionalista de Bolsonaro, é preciso estar atento às suas especificidades, que se explicam pela própria posição subalterna que o Brasil ocupa no sistema capitalista. Segundo Michael Lowy (2019), enquanto boa parte da extrema direita mundial denuncia a globalização neoliberal, em nome de um protecionismo do nacionalismo econômico, Bolsonaro propõe um programa econômico 
ultraliberal, com mais globalização e privatizações. Nesse sentido, Lowy (2020) destaca que o neofascismo de Bolsonaro é totalmente identificado com o neoliberalismo. A despeito do discurso ultranacionalista e patriótico, o sociólogo marxista argumenta que o Governo Bolsonaro é completamente subordinado ao imperialismo norte-americano, do ponto de vista econômico, diplomático e militar. Sobre esse aspecto, Demian Melo (2019) ressalta uma preciosa passagem dos "Cadernos do Cárcere", numa nota dedicada às relações internacionais, em que Antônio Gramsci diz que:

com frequência, o chamado "partido do estrangeiro" não é propriamente aquele que é habitualmente apontado como tal, mas precisamente o partido mais nacionalista, que, na realidade, mais do que representar as forças vitais do próprio país, representa sua subordinação e servidão econômica às nações ou a um grupo de nações hegemônicas (GRAMSCl, 2000, p.20).

Como nos apontam Luis Filgueiras e Graça Duck (2019), em síntese, o governo Bolsonaro é o modo de conjunção especificamente brasileiro - do neoliberalismo com o neofascismo. As políticas neoliberais iniciadas com Michel Temer e aprofundadas com Jair Bolsonaro trazem os traços marcantes dos interesses da burguesia associada ao capital internacional. Em uma perspectiva de longo prazo, do ponto de vista estrutural, as aplicações dessas políticas se manifestarão no aprofundamento da dependência, no aumento da desindustrialização, na redução do mercado interno, e no consequente aumento da desigualdade social e da pobreza (FILGUEIRAS; DUCK, 2019).

A forma com que Bolsonaro tem lidado com a pandemia do novo coronavírus, demonstra o caráter autoritário e obscurantista de sua política. O presidente do Brasil vem tentando impor, contra a Organização Mundial da Saúde (OMS), contra o Congresso, os governos estaduais e contras os seus próprios ministros da Saúde uma política cega de recusa das medidas sanitárias mínimas, imprescindíveis para tentar ao menos limitar as consequências da crise (LOWY, 2020). Segundo Michael Lowy (2020), o posicionamento de Bolsonaro perante a pandemia revela traços de um social-darwinismo, que é uma das características típicas do fascismo. Em uma entrevista coletiva, no dia 
28 de abril, quando um reporte disse à Bolsonaro que o Brasil tinha ultrapassado o número de mortes da China, o presidente respondeu: "E daí? Quer que eu faça o quê?" (G1, 2020); mostrando, desta forma, uma total indiferença em relação à morte de milhares de Brasileiros. Afinal, como diz a própria campanha do governo, "o Brasil não pode parar".

O negacionismo de Jair Bolsonaro ante a pandemia revela mais um aspecto que o relaciona à ideologia fascista. Segundo Sena Júnior (2019), a dimensão anti-intelectual e anticientificista de alguns governos na atualidade, sobretudo governo brasileiro, abertamente hostil à ciência, nos remetem a analogias com a Alemanha nazista. Em "Como funciona o fascismo" (2018) Jason Stanley assinala que o antiintelectualismo é uma das características típicas da política fascista. O autor estadunidense argumenta que a política fascista procura minar o discurso público, atacando e desvalorizando a educação, a especialização e a linguagem. Para Stanley (2018), uma vez que se deslegitima as universidades - acusando-as sobretudo de doutrinação marxista - e os especialistas, os políticos fascistas se veem livres para criar as suas próprias realidades, formatadas a partir de suas vontades individuais. No Brasil, o discurso obscurantista tem respaldo principalmente nos setores mais retrógrados do neopentecostalismo, uma das principais bases sociais do bolsonarismo.

\section{CONSIDERAÇÕES FINAIS}

Em 1970, analisando a atualidade da discussão elaborada em "Fascismo e ditaduras", Nicos Poulantzas argumentou que o fascismo assim como outros regimes de exceção - não são fenômenos limitados no tempo. O marxista grego sustentou que o ressurgimento do fascismo ainda seria possível, mesmo que não se revista agora exatamente das mesmas formas e condições históricas que se revestiu do passado. Na esteira desse argumento, em 1981, no artigo "Notas sobre o fascismo na América Latina", Florestan Fernandes assinalou que o fascismo não teria perdido, como realidade histórica, o seu significado político e nem a sua influência ideológica. Entretanto, o debate sobre o conceito e a possibilidade do ressurgimento do fascismo está mais aceso no início do século XXI, quando observamos 
a ascensão de movimentos e partidos de extrema direita em diversas partes do mundo. Nesse sentido, concordamos com a observação de Armando Boito Jr (2019), na qual acredita ser possível o surgimento do fascismo na atualidade, mesmo que o fenômeno assuma formas distintas de sua matriz histórica.

Nesse cenário, a partir dos elementos analisados no artigo, consideramos que Jair Bolsonaro é um neofascista. O prefixo "neo" se justifica pelas especificidades do bolsonarismo e pela própria particularidade histórica em relação ao surgimento do fascismo clássico. O que chamamos de bolsonarismo é um movimento reacionário de massas - movido por discursos misóginos, racistas, anticomunista e obscurantistas -, organizado sobretudo pelas redes sociais. O movimento de Bolsonaro tem suas origens e a sua principal base nas camadas intermediárias da sociedade brasileira. Contudo, assim como no fascismo histórico, o bolsonarismo ultrapassa as fronteiras de sua classe originária e também consegue penetrar nas classes subalternas, principalmente através de um discurso que apela a uma moralidade cristã reacionária. O neofascismo de Jair Bolsonaro está intimamente ligado aos interesses da burguesia associada ao capital internacional, identificando, assim, o neoliberalismo como sua verdadeira "afinidade eletiva".

\section{REFERÊNCIAS BIBLIOGRÁFICAS:}

BENSAID, Daniel. Fragments mécréants. Mythes identitaires et République imaginaire. Paris: Lignes, 2005.

BOITO JR., Armando. O neofascismo no Brasil. Boletim LIERI, UFRRJ, n.1, maio 2019 . http://laboratorios.ufrrj.br/lieri/wpcontent/uploads/sites/7/2019/05/Boletim-1-O-Neofascismo-noBrasil.pdf

BORON, Atílio A. Caracterizar o governo de Jair Bolsonaro como "fascista" é um erro grave. Brasil de Fato. 02 de janeiro de 2019. Disponível em: <https://www.brasildefato.com.br/2019/01/02/artigo-orcaracterizar-o-governo-de-jair-bolsonaro-como-fascista-e-um-errograve/>. 
BRAZ, Marcelo. O golpe nas ilusões democráticas e a ascensão do conservadorismo reacionário. Serv. Soc. Soc. [online]. 2017, n.128, pp.85103. ISSN 2317-6318.

DARDOT, Pierre; LAVAL, Christian. A nova razão do mundo: ensaio sobre a sociedade neoliberal. São Paulo: Boitempo, 2016.

FILGUEIRAS, Luiz e DUCK, Graça. O neoliberalismo neofascista do governo Bolsonaro e os desafios para a esquerda. Marxismo21.org, 2019. Disponível: https://marxismo21.org/wpcontent/uploads/2019/12/Luiz-Filgueiras-e-Gra\%C3\%A7a-Druck.pdf

O governo Bolsonaro, Neofascismo e a resistência democrática.. Le Monde Diplomatique Brasil, novembro de 2018. Acessível em https://diplomatique.org.br/o-governo- bolsonaro-oneofascismo-e-a-resistencia-democratica/

FINCHELSTEIN, Frederico. From fascism to populism in history. California: University of California Press, 2017.

FOUCAULT, Michel. O Nascimento da Biopolítica. São Paulo: Martins Fontes, 2008.

FOLHA DE SÃO PAULO. Leia na íntegra do discurso de Bolsonaro na cerimônia de posse no congresso, 01/01/2019.

GRAMSCl, Antônio. Cadernos do Cárcere. Vol.3. Rio de Janeiro: Civilização Brasileira, 2000.

HAYEK, Friedrich. O Caminho da Servidão. São Paulo: Instituto Luidwig Von Mises, 2010.

IANNI, Octavio. Neoliberalismo e nazi-fascismo. Crítica Marxista, São Paulo, Xamã, v.1, n.7, 1998, p.112-120. 
LOWY, Michael. Conservadorismo e extrema direita na Europa e no Brasil. Serv. Soc. Soc., São Paulo, n. 124, p. 652-664, out./dez. 2015. Neofascismo: um fenômeno planetário - o caso Bolsonaro. Bresserpereira.org. $2019 . \quad$ Disponível: http://www.bresserpereira.org.br/Terceiros/2019/outubro/19.10Neofascismo-e-Bolsonaro.pdf O Neofacista diante da Pandemia. Blog da Boitempo2020. Disponível:https://blogdaboitempo.com.br/2020/04/28/michaellowy-o-neofascista-bolsonaro-diante-da-pandemia/ MANDEL, ERNST. Trotsky como alternativa. São Paulo: Xamã, 1995 MATTOS, Marcelo Badaró. Governo Bolsonaro: neofascismo e autocracia burguesa no Brasil. São Paulo: Usina Editorial, 2020.

MELO, Demian. Bolsonaro, fascismo e neofascismo. In: Marx e o Marxismo 2019: Marxismo sem tabus - Enfrentando opressões, 2019, Niterói. Anais do Marx e o Marxismo 2019: Marxismo sem tabus Enfrentando opressões, 2019. v. 1. p. 1-11.

MIGUEL, Luis Felipe. Caminhos e descaminhos da experiência democrática no brasil. revista sinais sociais, v. 22, p. 99-129, 2017.

MISES, Luidwig Von. A Ação Humana. São Paulo: Instituto Luidwig Von Mises, 2010.

MORAES, Reginaldo C. Neoliberalismo e neofascismo - és lo mismo pero no és igual?. Crítica Marxista, São Paulo, Xamã, v.1, n.7, 1998, p.121126.

O GLOBO. "E daí? Lamento. Quer que eu faça o que? Diz Bolsonaro sobre mortes por Covid, 28/04/2020. 
POULANTZAS, Nicos. Fascismo e ditaduras: a III Internacional face ao fascismo. Vol.2. Porto: Portucalense, 1972.

ROSAS, Fernando. Salazar e os fascismo: ensaio breve de história comparada. Lisboa: Tinta-da-China, 2019.

SENA JÚNIOR, C. Obscurantismo e a anticientificismo no Brasil bolsonarista: anotações sobre a investida protofascista contra a inteligência e a ciência no Brasil. Cadernos do GPOSSHE On-line, v. 3, n. 1, p. 21-49, 3 out. 2019.

STANLEY, Jason. Como funciona o fascismo. A política do "nós" contra "eles". Porto Alegre: L\&M, 2018.

TOGLIATTI, Palmiro. Lições sobre o fascismo. São Paulo: Ciências Humanas, 1978.

TRAVERSO, Enzo. The new fasces of fascism. Londres: Verso, 2019

TROTSKY, Leon. Como esmagar o Fascismo. São Paulo: Autonomia Literária, 2018

WEBER, Mateus. O neofascismo brasileiro: um debate sobre a sua possibilidade histórica. (Blog). ODELA - UFRGS. 2019. 